\title{
Laparoscopic versus Open Non-anatomical Hepatectomy for Hepatocelluar Carcinoma in Cirrhotic Liver
}

\author{
H. Said, ${ }^{1}$ MD, Mohamed Elnagar, ${ }^{1}$ MD, MRCS; Ahmed Helal, ${ }^{2}$ MD.
}

\section{1) General Surgery Department, Faculty of Medicine, Ain Shams University.} Egypt.

2) Department of Tropical Medicine, Faculty of Medicine, Ain Shams University, Egypt.

Background: Although the use of laparoscopy has gradually gained favor, the short-term benefits generally observed with laparoscopy applied to patients undergoing partial hepatic resection remains unclear. The aim of the present study was to report and compare the results of patients undergoing laparoscopic hepatectomy $(\mathrm{LH})$ and open hepatectomy $(\mathrm{OH})$ in short term follow up.

Patients and methods: This is a controlled randomized prospective study conducted in Ain Shams University Hospitals between December 2012 and April 2015 comparing laparoscopic non-anatomic hepatectomy (15 patients) and open non-anatomic hepatectomy (15 patients) in the management of HCC in cirrhotic patients.

Results: There were no significant differences between both groups regarding operative time $(145 \pm 43 \mathrm{~min} V s 152 \pm 49.92 \mathrm{~min} P=0.679)$, blood loss $(376 \pm 250 \mathrm{ml} V s 526 \pm 307 \mathrm{ml} \mathrm{P}=0.156)$. Overall complication rate $(46.7 \%$ Vs $53.3 \% P=0.715)$, post-operative ascitis $(P=0.156)$ and overall thirty day mortality ( $0 \%$ Vs $6.7 \% P=0.31)$. Safety margin was adequate in both groups. Hospital stay was significantly lower in the group of $L H(9.8 \pm 3.76$ days $)$ than in the group of OH $(15 \pm 4.76$ days $)(P=0.001)$.

Conclusion: Laparoscopic non-anatomical hepatectomy for HCC in cirrhotic liver is equally safe and feasible in segments II to VI.

Key words: Laparoscopic hepatectomy, open non-anatomical hepatectomy, hepatocelluar carcinoma, cirrhotic liver.

\section{Introduction:}

Hepatic surgery is one of the most challenging and complex procedures requiring considerable expertise. Laparoscopic hepatic surgery requires additional advanced skills. ${ }^{1}$ Laparoscopic liver resection was first performed in the 1990s, and the first formal anatomical resection in $1996 .^{2}$ Despite the technical difficulties, more centers have been using laparoscopy in hepatic surgery in the last decade.

The Louisville Statement in 2008 suggests that laparoscopic hepatectomy (LH) has become a widely accepted surgical procedure for liver lesions. ${ }^{3}$ Studies from different medical centers have confirmed the safety and feasibility of open hepatectomy $(\mathrm{OH})$ for patients with an acceptably low complication rate and satisfying oncological outcomes. ${ }^{4}$ Although the use of laparoscopy has gradually gained favor, the short-term benefits generally observed with laparoscopy applied to patients undergoing partial hepatic resection remains unclear. ${ }^{5}$ Advances in laparoscopic techniques and instruments have rendered laparoscopic procedures more safe and feasible in surgical operations with less blood loss, shorter hospital stay and without compromised complication rate or oncological outcomes compared with open 
surgery. 6

The aim of the present study was to report and compare the results of patients undergoing laparoscopic hepatectomy ( $\mathrm{LH})$ and open hepatectomy $(\mathrm{OH})$ in short term follow up.

\section{Aim of this study:}

Was to compare between laparoscopic hepatectomy ( $\mathrm{LH})$ and open hepatectomy $(\mathrm{OH})$ in short term follow up.

\section{Patients and methods:}

This is a controlled randomized prospective study conducted in Ain Shams University Hospitals between December 2012 and April 2015. Thirty patients were included in this study and were divided into two groups (LH and $\mathrm{OH}$ ); fifteen patients in each group.

Inclusion criteria for patients undergoing either $\mathrm{LH}$ or $\mathrm{OH}$ with

- Hepatocellular carcinoma.

- $\quad$ Patients with liver cirrhosis.

- Child-Pugh classification A.

- Solitary HCC.

- Tumor size more than $3 \mathrm{~cm}$.

- Tumor size less than $3 \mathrm{~cm}$ if sub-capsular.

- $\quad$ Segment II, III, IVb, V and VI for laparoscopic group.

- Non-anatomical resection.

Exclusion criteria:

- Child-Pugh classification B or C.

- $\quad$ Previous treatment of HCC.

- Tumor less than $3 \mathrm{~cm}$ central.

- $\quad$ Satellite nodules.

- $\quad$ Segmental portal vein thrombosis.

- $\quad$ Previous upper abdominal surgery.

Hepatocellular carcinoma was diagnosed with typical criteria by the triphasic CT with or without AFP elevation. Triphasic CT determined number, site, size of the HCC, major vascular invasion, lymph node metastasis and ascitis.

Bone scan and chest $\mathrm{CT}$ in some patients with poor prognostic criteria like AFP $>400$.

All patients were evaluated by liver function test, coagulation profile for calculation of Child-Pugh classification. Routine preoperative assessment complete blood count, kidney function as well as routine cardio-respiratory evaluation were done.

Surgical technique:

Laparoscopic Hepatectomy (LH):All operations were performed under general anesthesia. Each patient was placed in supine position, legs apart and tilted $30^{\circ}$ to the left or right according to the lesion location. The primary surgeon stood between the patient's legs with one assistant on either side. Left semi-decubitus position was used if the lesion was in segment VI with the surgeons stood on the left side of the patient. Three 10-12 mm trocars were inserted routine and the forth $5 \mathrm{~mm}$ was inserted on demand. First one was placed supra-umbilical for 30o scope, other trocars sites were planned case by case according to the site of the lesion. Start with abdominal exploration. Limited liver mobilization according to the need. Liver parenchymal transection was performed using a combination of harmonic scalpel and bipolar forceps. Small vessels were coagulated directly and large vessels (diameter $\geq 3 \mathrm{~mm}$ ) were occluded using titanium clip or Hem-o-lok clamping. Major vessels were divided by application of vascular stapling devices (once for lesion in segment II and III). During liver transection, the intravenous fluid was carefully controlled. Central venous pressure was maintained at a low level ( $<5 \mathrm{~mm} \mathrm{Hg}$ ). Laparoscopic control of bleeding included a transient increase in pneumo-peritoneum pressure to $16 \mathrm{mmHg}$. The resected specimens were placed in a plastic retrieval bag and removed through a widening in port site. Abdominal drainage tube was usually inserted Figure (1).

Open Hepatectomy (OH): All operations were performed under general anesthesia. The patients were placed in the supine position. The liver resections were performed through a hooky stick incision. Start with exploration of the abdominal cavity and mobilization of the liver. The pedicle was prepared to enable performance of the Pringle maneuver when needed. Parenchymal transection was achieved with the harmonic scalpel. 

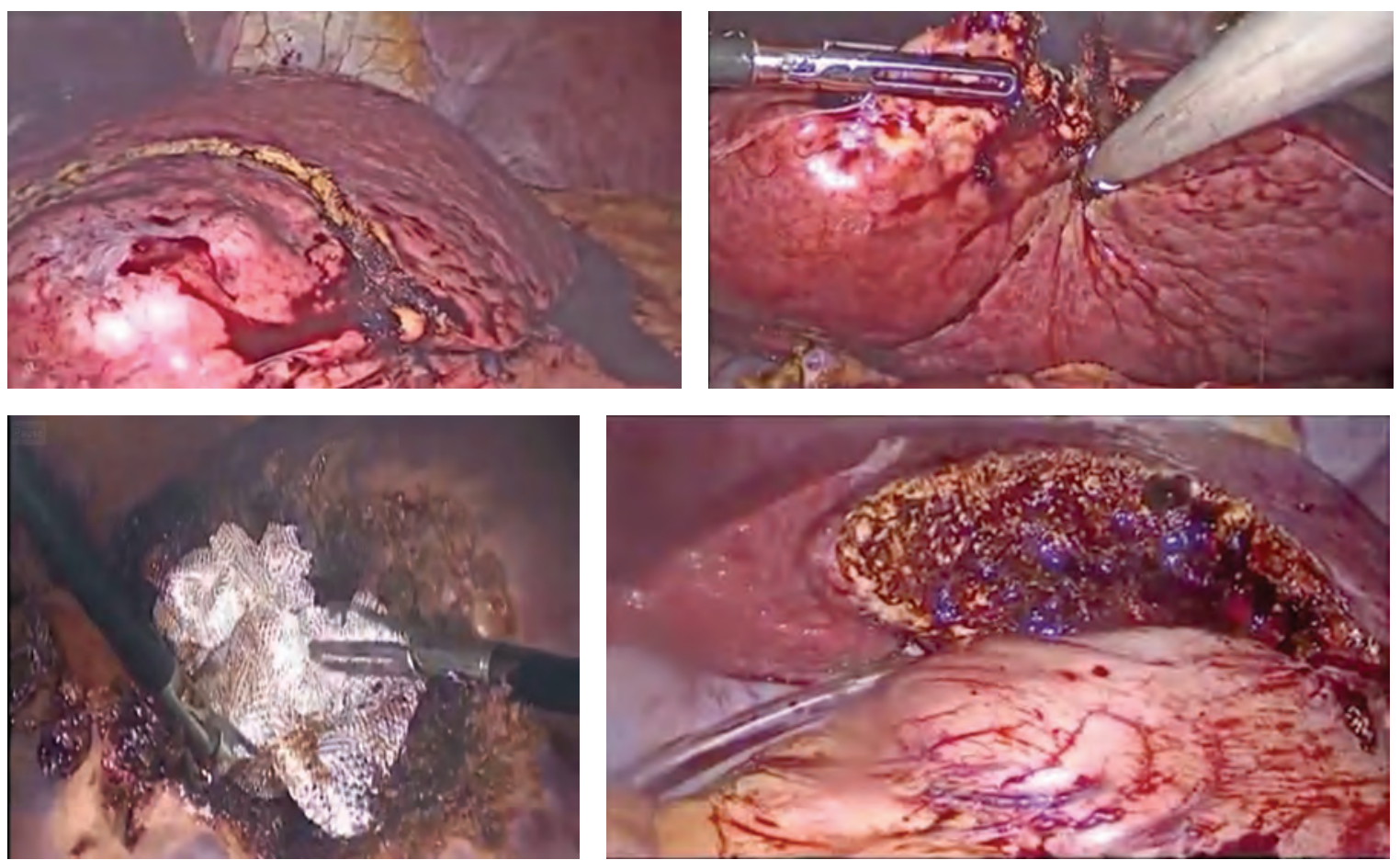

Figure (1): Laparoscopic hepatectomy: marking of tumor, excision of the tumor, homeostasis, liver after excision.
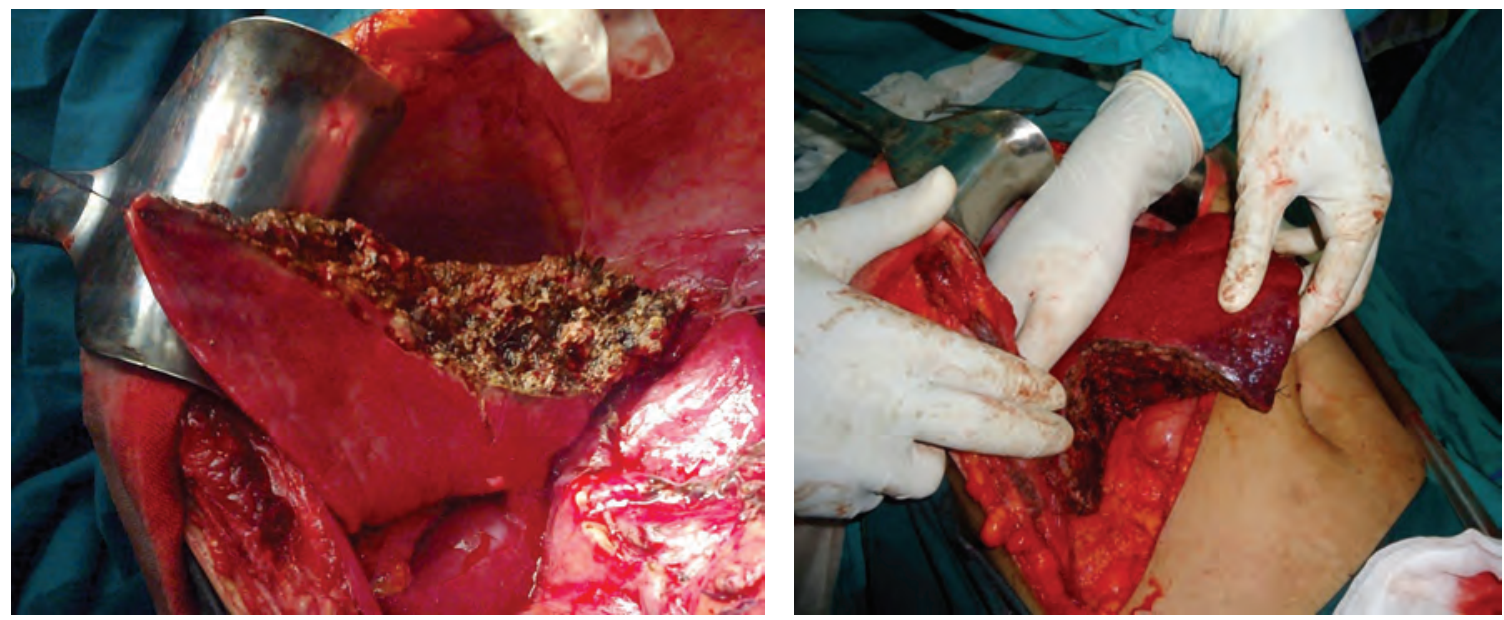

Figure (2): Open hepatectomy.

Control of minor bleeding was obtained with monopolar electrocoagulation. Clips or nonabsorbale sutures were used for ligation of major vessels. Abdominal drainage tube was usually inserted Figure (2).

All patients were transferred to the intensive care unit (ICU) after the operation and then transferred to the general ward when the condition became stable. Follow up laboratory daily and Doppler ultrasound twice weekly.

Comparisonbetweenboth groupsregarding operative time, intra-operative blood loss, blood transfusion, safety margin, hospital stay, post-operative ascitis, post-operative complications and mortality. Postoperative complications were stratified according to the Clavien-Dindo classification, ${ }^{7}$ and complications of grade III or greater were considered severe Table (1).

Statistical analysis: Analysis of data was done by IBM computer using SPSS (statistical program for social science version 16) as follows: description of quantitative variables as mean, SD and range, description of qualitative variables as number and 
Table (1): The Clavien-Dindo Classification of Surgical Complications.

\begin{tabular}{|c|c|}
\hline Grades & Definition \\
\hline \multirow[t]{2}{*}{ Grade I: } & $\begin{array}{l}\text { Any deviation from the normal postoperative course without the need } \\
\text { for pharmacological treatment or surgical, endoscopic and radiological } \\
\text { interventions. }\end{array}$ \\
\hline & $\begin{array}{l}\text { Allowed therapeutic regimens are: drugs as antiemetics, antipyretics, analgesics, } \\
\text { diuretics and electrolytes and physiotherapy. This grade also includes wound } \\
\text { infections opened at the bedside. }\end{array}$ \\
\hline Grade II: & $\begin{array}{l}\text { Requiring pharmacological treatment with drugs other than such allowed for } \\
\text { grade I complications. } \\
\text { Blood transfusion and total parenteral nutrition are also included. }\end{array}$ \\
\hline Grade III: & Requiring surgical, endoscopic or radiological intervention. \\
\hline $\begin{array}{l}\text { Grade } \\
\text { III-a: }\end{array}$ & Intervention not under general anesthesia. \\
\hline $\begin{array}{l}\text { Grade } \\
\text { III-b: }\end{array}$ & Intervention under general anesthesia. \\
\hline Grade IV: & $\begin{array}{l}\text { Life-threatening complications (including CNS complications) } \ddagger \text { requiring IC/ } \\
\text { ICU-management. }\end{array}$ \\
\hline $\begin{array}{l}\text { Grade } \\
\text { IV-a: }\end{array}$ & Single organ dysfunction (including dialysis). \\
\hline $\begin{array}{l}\text { Grade } \\
\text { IV-b: }\end{array}$ & Multi-organ dysfunction. \\
\hline Grade V: & Death of a patient. \\
\hline Suffix $\langle\mathrm{d}\rangle$ : & $\begin{array}{l}\text { If the patient suffers from a complication at the time of discharge, the suffix } \\
\text { "d" (for 'disability') is added to the respective grade of complication. This label } \\
\text { indicates the need for a follow-up to fully evaluate the complication. }\end{array}$ \\
\hline
\end{tabular}

$\ddagger$ brain hemorrhage, ischemic stroke, subarachnoidal bleeding,but excluding transient ischemic attacks (TIA);IC: Intermediate care; ICU: Intensive care unit. Dindo D., Demartines N., Clavien P.A.; Ann Surg. 2004; 244: 931-937.

Table (2) Demographic data:

\begin{tabular}{|l|l|l|l|}
\hline & \multicolumn{1}{|c|}{$\begin{array}{c}\text { Group A: } \\
\text { Laparoscopic hepatectomy }\end{array}$} & $\begin{array}{c}\text { Group B: } \\
\text { Open hepatectomy }\end{array}$ & P value \\
\hline Sex (number /frequency) & $\begin{array}{l}\text { Male 12 (80\%) } \\
\text { Female 3 (20\%) }\end{array}$ & $\begin{array}{l}\text { Male 11 (73.3\%) } \\
\text { Female 4 (26.7\%) }\end{array}$ & 0.66 \\
\hline Age (mean \pm SD) & $52.66 \pm 6.52$ & $58.6 \pm 7.61$ & 0.68 \\
\hline HCV (number /frequency) & $\begin{array}{l}\text { Yes 14(93.3 \%) } \\
\text { No 1 (6.7\%) }\end{array}$ & $\begin{array}{l}\text { Yes 13 (86.7\%) } \\
\text { No 2 (13.3\%) }\end{array}$ & 0.14 \\
\hline HBV (number /frequency) & $\begin{array}{l}\text { Yes 2 (13.3\%) } \\
\text { No 13 (86.7\%) }\end{array}$ & $\begin{array}{l}\text { Yes 1 (93.3\%) } \\
\text { No 14 (6.7\%) }\end{array}$ & 0.54 \\
\hline $\begin{array}{l}\text { PORTAL HYPERTENSION } \\
\text { (number /frequency) }\end{array}$ & $\begin{array}{l}\text { Yes 3 }(20 \%) \\
\text { No 12 (80\%) }\end{array}$ & $\begin{array}{l}\text { Yes 3 }(20 \%) \\
\text { No 12 (80\%) }\end{array}$ & 1 \\
\hline AFP (mean \pm SD) & $270.93 \pm 617.1$ & $184.66 \pm 234.44$ & 0.617 \\
\hline Tumor size (mean \pm SD) & $4.3 \pm 1.6$ & $5.7 \pm 1.3$ & 0.179 \\
\hline
\end{tabular}


Table (3) Comparison between I-O data, post-operative data and safety margin:

\begin{tabular}{|l|l|l|l|}
\hline & $\begin{array}{l}\text { Group A } \\
\text { Laparoscopic hepatectomy }\end{array}$ & $\begin{array}{l}\text { Group B } \\
\text { Open hepatectomy }\end{array}$ & P value \\
\hline Operative time (mean \pm SD) & $145.53 \pm 43.34$ & $152 \pm 49.92$ & 0.679 \\
\hline I-O blood loss (mean \pm SD) & $376 \pm 256.92$ & $526.66 \pm 307.56$ & 0.156 \\
\hline Drain amount (mean \pm SD) & $283.33 \pm 180.93$ & $396.67 \pm 222.37$ & 0.156 \\
\hline $\begin{array}{l}\text { Postoperative complication (number } \\
\text { /frequency) }\end{array}$ & $\begin{array}{l}\text { Yes 7 (46.7\%) } \\
\text { No 8 (53.3\%) }\end{array}$ & $\begin{array}{l}\text { Yes 8 (53.3\%) } \\
\text { No 7 (46.7\%) }\end{array}$ & 0.715 \\
\hline Complication grade (median/range) & $1(0-3)$ & $2(1-5)$ & 0.704 \\
\hline Hospital stay (mean \pm SD) & $9.8 \pm 3.76$ & $15 \pm 4.76$ & 0.001 \\
\hline Mortality (number /frequency) & No 15 (100\%) & $\begin{array}{l}\text { No 14(93.3) } \\
\text { Yes 1 (6.7\%) }\end{array}$ & 0.31 \\
\hline Safety margin (number /frequency) & $\begin{array}{l}\text { Yes 13 (86.7\%) } \\
\text { No 2 (13.3\%) }\end{array}$ & $\begin{array}{l}\text { Yes 14 (93.3\%) } \\
\text { No 1(6.7\%) }\end{array}$ & 0.543 \\
\hline
\end{tabular}

percentage, Chi-square test was used to compare matched pairs before and after intervention. $P$ value $>0.05$ was considered insignificant, $\quad \mathrm{P}<0.05$ was considered significant, $\mathrm{P}<0.001$ was considered highly significant.

\section{Results:}

Thirty patients were included in this study divided into 2 groups. Group (A), fifteen patients undergoing laparoscopic hepatectomy and group (B), fifteen patients undergoing open hepatectomy. Demographic data of both groups were comparable Table (2). In the LH group males to females ratio was (12:3), while in $\mathrm{OH}$ group males to females ratio was (11:4). Mean age in group A was $52.6 \pm 6$ and in group B was 58.6 \pm 7 . Thirteen patients in group A had HCV, one patient had HBV and one patient had HCV and HBV. In group B thirteen patients had $\mathrm{HCV}$, one had HBV and one had cryptogenic cirrhosis. All patients in both groups were CTP A and 20\% of both group had manifestation of portal hypertension (spleenomegally and platelet $<100$ ).

Tumor data regarding size, site and Alpha Feto-protein were comparable. In group A tumor size ranged from 2-7 cm (mean 4.3 \pm 1.6 ), AFP ranged from 8-2400 (mean $270 \pm 617)$ and commonest tumor sites were segment IVb (26.7\%) followed by segment
III, V and VI (20\% for each). In group B tumor size ranged from 3-9 cm (mean 5.7 41.3 ), AFP ranged from 14-900 (mean 184 \pm 231 ) and commonest tumor sites were segment IVa, V and VII (20\% for each) followed by segment VI (13.3\%).

Operative and postoperative outcomes: Intra-operative data, post-operative data and adequate safety margin were all non significant differences between both groups except for hospital stay. Mean operative time was $145 \pm 43 \mathrm{~min}$. in group A versus $152 \pm 49.92$ min in group $\mathrm{B}(\mathrm{P}=0.679)$. In spite of lower blood loss in group A $(376 \pm 250)$ than in group B $(526 \pm 307)$ but it was statistically non significant $(\mathrm{P}=0.156)$.

Conversion to open occurred in two cases, first was for apparent bleeding and second was for colonic injury at hepatic flexure during mobilization of the right lobe. Primary repair was done with smooth post-operative course.

Overall morbidity was (46.7\%) for $\mathrm{LH}$ versus $(53.3 \%)$ for $\mathrm{OH} ; \mathrm{P}=0.715)$ and severity of complications were not different between the two groups. Specifically, the rate of minor morbidity (Clavien- Dindo grades I-II) was similar (33.3\% for LH; Vs $40 \%$ for $\mathrm{OH} \mathrm{P}=.67$ ), as was the rate of major morbidity (Clavien-Dindo grades III-V) (13.3\% in each group; $\mathrm{P}>.99$ ). There was no significant difference regarding ascitis 
between both groups $(\mathrm{P}=0.156)$. Overall thirty day mortality was ( $0 \%$ for LH versus $6.7 \%$ for $\mathrm{OH} ; \mathrm{P}=0.31$ ). Safety margin was adequate in both groups.

Length of hospital stay was significantly lower in group $\mathrm{A}(9.8 \pm 3.76$ days) than in group $\mathrm{B}(15 \pm 4.76$ days $)(\mathrm{P}=0.001)$.

\section{Discussion:}

Although recent studies suggested the feasibility of $\mathrm{LH}$, this procedure remains challenging and demands both laparoscopic and hepatobiliary surgery expertise especially in cirrhotic patients. ${ }^{8}$ One of the initial barriers to perform laparoscopic partial hepatic resection was concerned with the safety of laparoscopic hemostatic technique. Despite the technical difficulties, more centers have been using laparoscopy in hepatic surgery in the last decade. ${ }^{9}$

Liver resection has been associated with increased blood loss and blood product transfusion when compared with other surgical procedures leading to increase risk of short-term or long-term morbidity and mortality. ${ }^{10}$ Several factors may contribute to the decreased blood loss in laparoscopic hepatectomy. The application of laparoscopy allows more meticulous hemostasis, which offered the surgeons a very clear view with magnification. The raised intra-abdominal pressure from pneumo-peritoneum minimizes oozing of blood during the operation. ${ }^{11}$ In this study, blood loss decreased in LH group but not statistically significant ( $\mathrm{LH}$ vs. $\mathrm{OH}$ was 356 Vs $526 \mathrm{ml}$ with $\mathrm{P}$ 0.156). This finding may be due to early experience with laparoscopic hepatectomy or unlimited tumor size, as we had four cases with tumor $>5 \mathrm{~cm}$ and all of our patients had liver cirrhosis.

The largest meta-analysis up to date on the subject of $\mathrm{LH}$ versus $\mathrm{OH}$ reported a $59.9 \%$ lower risk of postoperative complications after LH. However, the decrease in complications was not universally observed among the included studies. Only 8 of those 26 studies even reported a liverspecific complication (bile leakage) and no significant difference was noted. ${ }^{12}$ However, in our study with regard to the short-term outcome of overall complications, there was no difference between the groups with regard to the significant complication rate $(46.7 \%$ Vs $53.3 \%$ : $\mathrm{P}=0.715$ ). Defined as ClavienDindo (CD) classification, the rate was for CDI \& II ( $33 \%$ vs. $40 \%$ ) for $\mathrm{LH}$ versus $\mathrm{OH}$ and for CD III-V was the same (13.3\%) for both. Respiratory complications were the most common complication. Bile leakage happened only in $\mathrm{OH}$. Regarding mortality within thirty days, it occurred in one patient in $\mathrm{OH}$ group.

Laparoscopic procedures may in fact also provide oncological benefits compared to open approach. In a recent study by Shi and colleagues, it was shown that a resection margin of $2 \mathrm{~cm}$ provided better long-term outcomes for HCC compared to the traditional $1 \mathrm{~cm}$. The results of this meta-analysis had shown that surgeons performing laparoscopic procedures returned wider histological tumour margins following resection when compared to the open approach. High definition magnification may provide easier assessment of the affected tissue and aid the surgeon to resect a tumour-free wide margin. ${ }^{13}$ In our study adequate safety margin $(>1 \mathrm{~cm})$ was achieved in both groups.

Decreased hospital stay has been shown to be a benefit of LH. The benefit is presumed to be related to the observed decrease in duration of intravenous narcotics and the time to oral intake. ${ }^{14} \mathrm{We}$ observed a significant decrease in hospital stay between both group (mean hospital stay was $9.8 \pm 3.76$ and $15 \pm 4.76$ for $\mathrm{LH}$ and $\mathrm{OH}$ groups respectively $\mathrm{P}=0.001$ ). Patients underwent laparoscopic hepatectomy showed better organ function reserve and faster postoperative rehabilitation in terms of ICU stay, first mobilization out of bed, starting oral intake and laboratory test results.

\section{Conclusion:}

Laparoscopicnon-anatomical hepatectomy for HCC in cirrhotic liver is equally safe and feasible in segments II to VI.

\section{Reference:}

1- Nguyen KT, Gamblin TC, Geller DA: World review of laparoscopic liver resection-2804 
patients. Ann Surg 2009; 250: 831-841.

2- Azagra JS, Goergen M, Gilbart E, Jacobs D: Laparoscopic anatomical (hepatic) left lateral segmentectomy: Technical aspects. Surg Endosc 1996; 10(7): 758-761.

3- Buell JF, Cherqui D, Geller DA, O'Rourke $\mathrm{N}$, et al: The international position on laparoscopic liver surgery. Ann Surg 2009; 250(5): 825-830.

4- Adam R, Frilling A, Elias D, et al: Liver resection of colorectal metastases in elderly patients. Br J Surg 2010; 97: 366-376.

5- Jensen EH, Vickers SM: The maximally invasive hepatobiliary surgeon: A dying breed. Arch Surg 2010; 145(11): 1118.

6- Afaneh C, Kluger MD: Laparoscopic liver resection: Lessons at the end of the second decade. Semin Liver Dis 2013; 33: 226-235.

7- Dindo D, Demartines N, Clavien PA: Classification of surgical complications: A new proposal with evaluation in a cohort of 6336 patients and results of a survey. Ann Surg 2004; 240(2): 205-213.

8- Dagher I, Di Giuro G, Dubrez J, Lainas P, Smadja C, Franco D: Laparoscopic versus open right hepatectomy: A comparative study. Am J Surg 2009; 198: 173-177.

9- Ito $\mathrm{K}$, Ito $\mathrm{H}$, Are $\mathrm{C}$, et al: Laparoscopic versus open liver resection: A matched-pair case control study. J Gastrointest Surg 2009; 13(12): 2276-2283.

10- Aramaki O, Takayama T, Higaki T, et al: Decreased blood loss reduces postoperative complications in resection for hepatocellular carcinoma. J Hepatobiliary Pancreat Sci 2014; 21: 85-91.

11- Inoue Y, Hayashi M, Tanaka R, Komeda K, Hirokawa F, Uchiyama K: Short-term results of laparoscopic versus open liver resection for liver metastasis from colorectal cancer: A comparative study. Am Surg 2013; 79(5): 495-501.

12- Croome KP, Yamashita MH: Laparoscopic versus open hepatic resection for benign and malignant tumors: An updated meta-analysis. Arch Surg 2010; 145(11): 1109-1118.

13- Twaij A, Pucher PH, Sodergren MH, Gall T, Darzi A, Jiao LR: Laparoscopic versus open approach to resection of hepatocellular carcinoma in patients with known cirrhosis: Systematic review and meta-analysis: World J Gastroenterol 2014; 20(25): 8274-8281.

14- Olsén MF, Wennberg E: Fast-track concepts in major open upper abdominal and thoracoabdominal surgery: A Review World $J$ Surg 2011; 35(12): 2586-2593. 